\title{
Colorectal Cancer Implantation Metastasis in Haemorrhiodectomy Wound, Case Report
}

\author{
Manal Algallai', Mohamed Moftah ${ }^{2 *}$, Muftah A. Manita ${ }^{3}$, Soad I. Eldruki ${ }^{4}$ \\ ${ }^{1}$ Department of General Surgery, Benghazi Medical Centre, Benghazi, State of Libya \\ ${ }^{2}$ Department of General Surgery, Benghazi Medical Center, Benghazi University, Benghazi, State of Libya \\ ${ }^{3}$ Department of Radiology, Benghazi Medical Center, Benghazi University, Benghazi, State of Libya \\ ${ }^{4}$ Department of Pathology, Benghazi Medical Centre, Benghazi, State of Libya \\ Email: ^mmoftah68@gmail.com
}

How to cite this paper: Algallai, M., Moftah, M., Manita, M.A. and Eldruki, S.I. (2019) Colorectal Cancer Implantation Metastasis in Haemorrhiodectomy Wound, Case Report. Open Journal of Gastroenterology, 9, 185-191.

https://doi.org/10.4236/ojgas.2019.99021

Received: August 3, 2019

Accepted: September 26, 2019

Published: September 29, 2019

Copyright $\odot 2019$ by author(s) and Scientific Research Publishing Inc. This work is licensed under the Creative Commons Attribution International License (CC BY 4.0).

http://creativecommons.org/licenses/by/4.0/

\begin{abstract}
Implantation metastasis from colorectal cancer into haemorroidectomy wound is very rare. The management of this condition remains controversial. We report a case of 68-year-old man with perianal soft tissue lesion biopsied and histopathology revealed an adenocarcinoma. Further investigation by colonoscopy and computed tomography scan revealed rectal adenocarcinoma. Pathological examination confirmed that this lesion was a distant metastasis from rectal cancer. The case was discussed at the multidisplinary meeting and the patient was advised to undergo long course neoadjuvant chemoradiotherapy followed by anterior resection and local excision of perianal metastasis. This case will be treated with long course neoadjuvannt chemoradiotherapy and after six weeks from treatment completion the plan is to perform sphincter sparing anterior resection and local excision of perianal implanted tumor.
\end{abstract}

\section{Keywords \\ Colorectal Cancer, Haemorrhiodectomy, Wound}

\section{Introduction}

Rectal cancer implantation into post hemorrhoidectomy wound is a very rare type of distant metastasis. It accounts for less than $1 \%$ of all cases of colorectal metastasis. In 1954, Guiss reported the first case of rectal cancer metastasis to an anal fistula [1].

Though many case reports have described implantation of tumor cells in perianal fistulae [2]-[13], only very a few papers have reported implantation in 
hemorrhoidectomy wound [4] [13]-[17].

These lesions are commonly mistaken as benign perianal abscesses or fistulae [14]. The pathogenesis of this type of distant metastasis remains unknown. The presence of a breach in skin at the site of fissure, fistula or hemorrhoidectomy wound may explain how exfoliated tumor cells implant into these abnormal areas, but this would not explain how tumor cells would implant on intact hemorrhoidal skin tags [18].

Iatrogenic tumor implantation may result from various medical procedures used during diagnosis or treatment of a malignancy [19]. The main clinical feature of the condition is a nodule at the operation's incision site. Diagnosis requires high index of suspicion and should warrant biopsy and pathological examination.

The treatment option was either neoadjuvant chemoradiotherapy followed by both low anterior resection and local excision of perianal metastasis or abdominoperineal resection.

The aim of this report is to present a rare case of a missed rectal adenocarcinoma presenting as an implanted tumor in haemorrhoidectomy scar and discuss controversies in managing this rare presentation.

\section{Case Report}

A 68-year-old male, who is known to have Diabetes Mellitus and Chronic obstructive pulmonary disease, presented to another hospital with history of rectal bleeding of six months duration. A diagnosis of grade II hemorrhoids made and he had Mulligan Morgan hemorrhoidectomy. A few months later, he developed a perianal fleshy lesion at 7 O'clock hemorrhoidectomy scar site. The lesion treated as granulation tissue and debridement performed on two occasions but this lesion progressively increased in size (Figure 1).

This patient was referred to our colorectal service at Benghazi Medical Centre complaining of per rectal bleeding and tenesmus one year after hemorrhoidectomy. Clinical examination was unremarkable apart from nodular perianal mass (Figure 1). There was no palpable mass on digital rectal examination. No groin lymph nodes could be felt on examination. He underwent a lower GI endoscopy, which revealed annular tumor at $10 \mathrm{~cm}$ from the anal verge (Figure 2). The tumor looked similar in appearance to the perianal lesion. Biopsies taken from this tumor showed intramucosal well to moderately differentiated adenocarcinoma of rectum (Figure 3(a) and Figure 3(b)).

Biopsies were also taken from the perianal lesion and pathological examination showed colonic mucosa with invasion of malignant tumor cells similar in appearance to the histology slide seen in the rectal tumor specimen. Immunohistochemistry of CK7 and CK 20 were not available at our laboratory.

A complete staging work-up found no other evidence of distant metastatic spread.

MRI of pelvis showed large iso to high intense mass measuring $6.0 \mathrm{~cm}$ (CC plane) $\times 4.5 \mathrm{~cm}$ (AP plane) with irregular outline noted at upper rectum, about 9 
$\mathrm{cm}$ from anal verge. The mass causes nearly complete obstruction of rectal lumen and presented with few internal low intense dots (represent vascular channels) (Figure 4(a) and Figure 4(b)-blue arrows). The mass invades the muscularis propria muscle from all around and comes in contact with mesorectal fascia. Another well-defined round like-mass slightly high intense to muscle measures $3.5 \mathrm{~cm}$ in diameter projecting out of anal verge (Figure 4(b)-red arrow). Enlarged lymph nodes of $5 \mathrm{~mm}$ diameter or less noted within mesorectal fascia at $7^{\text {th }}$ and $8^{\text {th }} \mathrm{O}^{\text {'clock }}$ and of $1 \mathrm{~mm}$ from mesorectal fascia (not shown). Single LN noted at para-mesorectal fascia (Figure 5(b)) and one enlarged LN along the internal iliac artery. There was no evidence of invasion to urinary bladder or seminal vesicle.

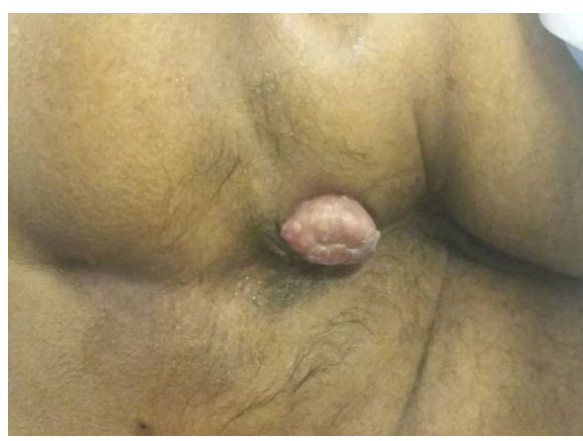

Figure 1. Perianal lesion (rectal metastasis).

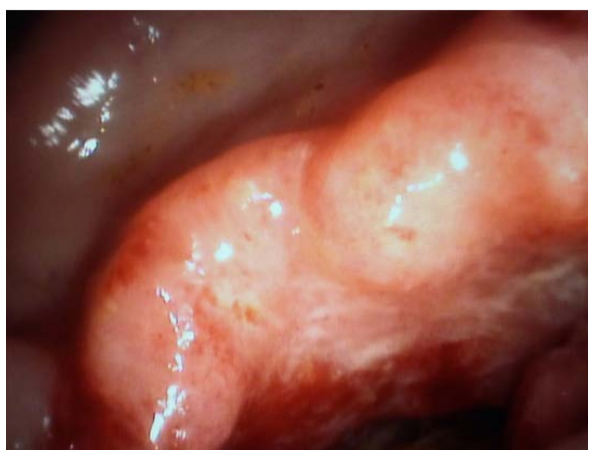

Figure 2. Endoscopic image of rectal tumour.

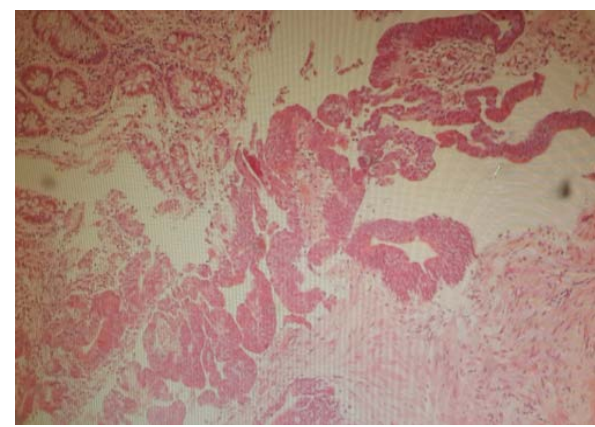

(a)

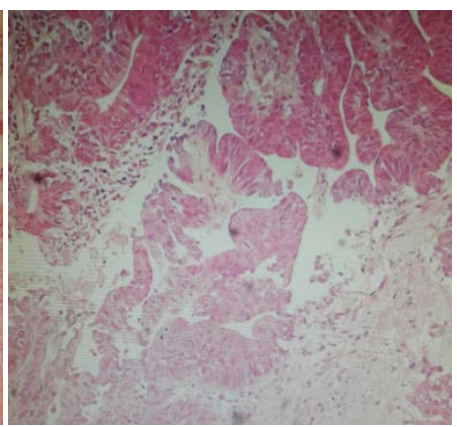

(b)

Figure 3. Low-power microscopic Sections showing moderately differentiated, Adenocarcinoma of the rectal mucosa ( $\mathrm{H} \& \mathrm{E} \times 40 \mathrm{xs})$. 


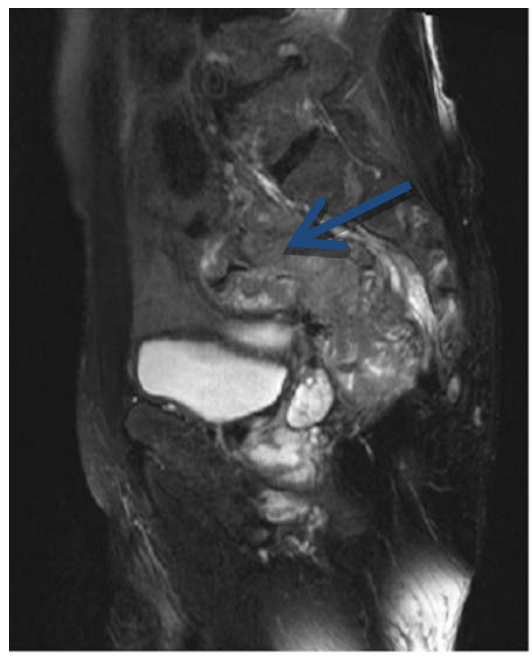

(a)

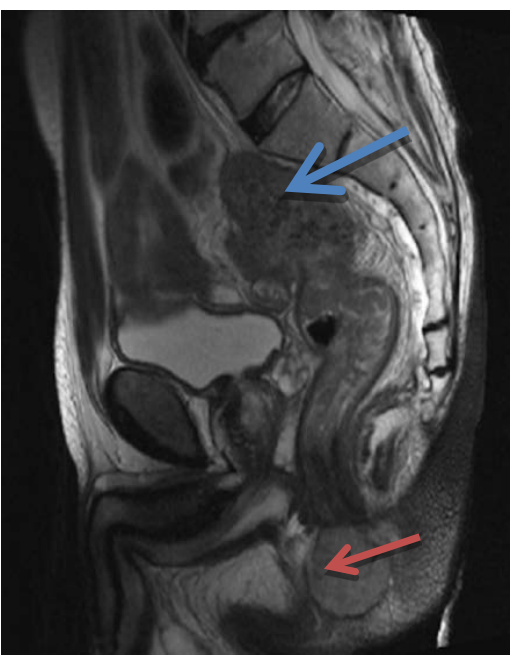

(b)

Figure 4. T2WI sagittal plane showing fungating mass at upper rectum and extends to mid-rectum (blue arrows). Slightly high intense mass (perianal metastasis) distal to anal verge (high protein content) (red arrow).

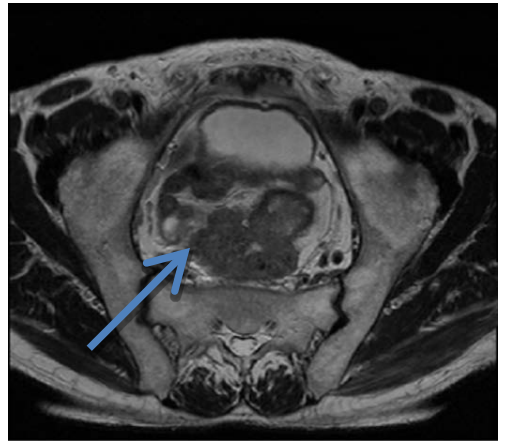

(a)

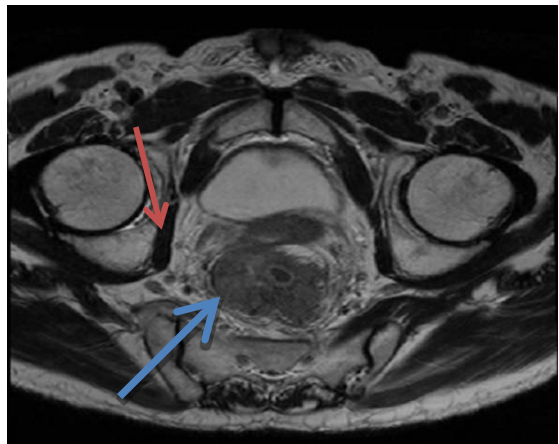

(b)

Figure 5. T2WI axial plane of pelvis showed well-defined irregular outline mass in the rectum with invasion beyond muscularis propria and abutting the mesorectal fascia (Figure 2(a)-large blue arrows), Single enlarged LN at para-mesorectal fascia (Figure 5(b)-red arrow).

Tumor marker Carci-noembryonic antigen (CEA) was $9.35 \mathrm{ng} / \mathrm{dl}$.

This case discussed at MDT meeting in Benghazi Medical Centre and the patient advised to have long-course neoadjuvant chemoradiotherapy, then restaging CT TAP and MRI followed either by total mesorectal excision and local metastatectomy or extra elevator abdominoperineal resection.

After discussion with the patient and obtaining informed consent, he commenced long course chemoradiotherapy.

$\mathrm{He}$ also decided to have total mesorectal excision and local excision of perianal implant six weeks after completing his chemoradiothereapy.

\section{Discussion}

Colorectal cancer cells are able to metastasize distally and implant into perianal 
skin. Most case reports on this problem indicate a breach in the surface barrier [19]. Various pathological and iatrogenic factors predispose to the occurrence of metastatic perianal disease. Some of these factors are preventable. As in our case, careful evaluation including history and endoscopy would have obviated the need for hemorrhoidectomy in the presence of rectal tumor.

The natural history of this distant metastasis is not known, but some authors reported cases that are still alive over 16 years after excision of perianal skin metastasis [20]. This may show that this type of metastasis is just a drop metastasis and may not have the potential to spread further and hence would not need radical surgery.

There is no specific recommendation for the management of colorectal cancer implantation metastases to perianal region, however, the main goals of treatment remain the same. Although the cure of cancer is the main goal, quality of life after surgery is an important issue to address as most patients prefer sphincter-saving surgery.

Some authors report to have performed APR [4] [11] [14] [18] [21] [22] while others have chosen local resection [2] [19] [23] [24] however, increasing recent reports have shown successful treatment with sphincter-saving surgery combined with local resection with or without radiotherapy without local recurrence.

In this case report, we highlight the importance of careful patient evaluation before contemplating perianal surgery to prevent drop metastasis and the need to discuss the available options for treatment of such rare presentation in the presence of scarce evidence to support each option.

\section{Conclusion}

Patients presenting with anorectal alarming symptoms should undergo endoscopic examination prior to performing any surgical intervention. Colorectal metastatic perianal disease considered potentially curable and could be resected by sphincter-saving surgery.

\section{Conflicts of Interest}

The authors declare no conflicts of interest regarding the publication of this paper.

\section{References}

[1] Guiss, R.L. (1954) The Implantation of Cancer Cell within a Fistula in Ano: Case Report. Surgery, 36, 136-139.

[2] Gupta, R., Kay, M. and Birch, D.W. (2005) Implantation Metastasis from Adenocarcinoma of the Colon into a Fistula-in-Ano: A Case Report. Canadian Journal of Surgery, 48, 162-163. https://doi.org/10.1007/s10350-004-0757-7-y

[3] Murata, A., Takatsuka, S., Shinkawa, H., Kaizaki, R., Hori, T. and Ikehara, T. (2014) A Case Report of Metastatic anal Fistula Cancer Treated with Neoadjuvant Chemotherapy. Japanese Journal of Cancer and Chemotherapy, 41, 1869-1871.

[4] Gomes, R.M., Kumar, R.K., Desouza, A. and Saklani, A. (2014) Implantation Me- 
tastasis from Adenocarcinoma of the Sigmoid Colon into a Perianal Fistula: A Case Report. Annals of Gastroenterology, 27, 276-279.

[5] Benjelloun El, B., Aitalalim, S., Chbani, L., Mellouki, I., Mazaz, K. and Aittaleb, K. (2012) Rectosigmoid Adenocarcinoma Revealed by Metastatic Anal Fistula. The Visible Part of the Iceberg: A Report of Two Cases with Literature Review. World Journal of Surgical Oncology, 10, 209. https://doi.org/10.1186/1477-7819-10-209

[6] Tomimaru, Y., Ohue, M., Noura, S., Tanida, T., Miyashiro, I., Yano, M., Ohigashi, H., Sasaki, Y., Ishikawa, O. and Imaoka, S. (2005) A Case of Anal Fistula Cancer Probably Developing from Intraluminal Dissemination of Rectal Cancer. Japanese Journal of Cancer and Chemotherapy, 32, 1776-1778.

[7] Ollinson, P.D. and Dundas, S.A. (1984) Adenocarcinoma of Sigmoid Colon Seeding into Pre-Existing Fistula in Ano. British Journal of Surgery, 71, 664-665.

https://doi.org/10.1002/bjs.1800710904

[8] Kouraklis, G., Glinavou, A., Kouvaraki, M., Raftopoulos, J. and Karatzas, G. (2002) Anal Lesion Resulting from Implantation of Viable Tumour Cells in a Pre-Existing anal Fistula. A Case Report. Acta Chirurgica Belgica, 102, 212-213.

https://doi.org/10.1080/00015458.2002.11679299

[9] Ishiyama, S., Inoue, S., Kobayashi, K., Sano, Y., Kushida, N., Yamazaki, Y. and Yanaga, K. (2006) Implantation of Rectal Cancer in an Anal Fistula: Report of a Case. Surgery Today, 36, 747-749. https://doi.org/10.1007/s00595-006-3236-3

[10] Wakatsuki, K., Oeda, Y., Isono, T., Yoshioka, S., Nukui, Y., Yamazaki, K., Nabeshima, S. and Miyazaki, M. (2008) Adenocarcinoma of the Rectosigmoid Colon Seeding into Pre-Existing Anal Fistula. Hepatogastroenterology, 55, 952-955.

[11] Kelly cristine de lacerda Rodrigues buzatti, igor guedes nogueira reis, isabelle reis daldegan and beatriz deoti silva Rodrigues (2018) Rectal Cancer Metastasis to an Anal Fissure. Journal of Clinical Gastroenterology and Treatment, 4, 61.

[12] Gomes, R.M., et al. (2014) Implantation Metastasis from Adenocarcinoma of the Sigmoid Colon into a Perianal Fistula: A Case Report. Annals of Gastroenterology, 27, 276-279.

[13] Rakoto-Ratsimba, H.N., Rakototiana, A.F., Rakotosamimanana, J. and Ranaivozanany, A. (2006) Anal Adenocarcinoma Revealed by a Fistula-in-Ano. Report of a Case. Annales de Chirurgie, 131, 564-566. https://doi.org/10.1016/j.anchir.2006.03.019

[14] Hsu, T.-C. and Lin, L. (2007) Implantation of Adenocarcinoma on Hemorrhoidectomy Wound. International Journal of Colorectal Disease, 22, 1407-1408. https://doi.org/10.1007/s00384-006-0179-5

[15] Timaran, C.H., Sangwan, Y.P. and Solla, J.A. (2000) Adenocarcinoma in a Hemorrhoidectomy Specimen: Case Report and Review of the Literature. The American Surgeon, 66, 789-792.

[16] Abbasakoor, F., Srivastava, V., Swarnkar, K. and Stephenson, B.M. (2004) Implantation Anal Metastases after Out-Patient Treatment of Haemorrhoids. Annals of the Royal College of Surgeons of England, 86, 38-39. https://doi.org/10.1308/003588404772614678

[17] Gujral, D.M., Bhattacharyya, S., Hargreaves, P. and Middleton, G.W. (2008) Metastatic Rectal Adenocarcinoma within Haemorrhoids: A Case Report. Journal of Medical Case Reports, 2, 128. https://doi.org/10.1186/1752-1947-2-128

[18] Liasis, L. and Papaconstantinou, H.T. (2016) Colorectal Cancer Implant in an External Hemorrhoidal Skin Tag. Proceedings (Baylor University. Medical Center), 29, 194-195. https://doi.org/10.1080/08998280.2016.11929414 
[19] Tranchart, H., Benoist, S., Penna, C., Julie, C., Rougier, P. and Nordlinger, B. (2008) Cutaneous Perianal Recurrence on the Site of Lone Star Retractor after J-Pouch Coloanal Anastomosis for Rectal Cancer: Report of Two Cases. Diseases of the Colon \& Rectum, 51, 1850-1852. https://doi.org/10.1007/s10350-008-9338-9

[20] Cantos-Pallarés, M., García-Armengol, J., Mulas-Fernández, C., Sancho-Moya, C., Fabra-Cabrera, I., Bruna-Esteban, M. and Roig-Vila, J.V. (2012) Perianal Cutaneous Metastases from Colorectal Adenocarcinoma. Revista Espanola de Enfermedades Digestivas, 104, 41-42.

[21] Meshikhes, A.W.N. (1998) An Unusual Implantation of a Rectosigmoid Adenocarcinoma into a Hemorrhoidectomy Scar. Annals of Saudi Medicine, 18, 242-243. https://doi.org/10.5144/0256-4947.1998.242

[22] Takahashi, R., et al. (2015) A Case of Metastatic Carcinoma of Anal Fistula Caused by Implantation from Rectal Cancer. Surgical Case Reports, 1, Article No. 123.

[23] Placer, C., Elósegui, J.L., Irureta, I., Mujika, J.A., Goena, I. and Enríquez Navascués, J.M. (2007) Metástasis cutánea perineal de adenocarcinoma tras cirugía de cáncer colorrectal. Cirugía Española, 82, 41-43. https://doi.org/10.1016/S0009-739X(07)71660-3

[24] De Friend, D.J., Kramer, E., Prescott, R., Corson, J. and Gallagher, P. (1992) Cutaneous Perianal Recurrence of Cancer after Anterior Resection Using the EEA Stapling Device. Annals of the Royal College of Surgeons of England, 74, 142-143. 